\title{
Artikel
}

\section{De wachtlijstproblematiek 'knaagt' aan de rechten van kinderen in gesloten jeugdhulp}

\author{
Een gesloten plaatsing slechts baseren op art. 3 lid 1 IVRK is geen oplossing
}

Mr. dr M.P. de Jong-de Kruijf*

\section{Inleiding}

Wachtlijsten in de jeugdzorg

Het thema 'wachtlijsten in de jeugdzorg' is een veelkoppig monster en een bijzonder hardnekkig probleem. De Inspectie Gezondheidszorg en Jeugd heeft geconstateerd dat kinderen met een ernstige ontwikkelingsbedreiging onvoldoende worden beschermd omdat zij niet tijdig de juiste hulp krijgen. ${ }^{1}$ Het probleem speelt bij Veilig Thuis (de doorlooptijd van een onderzoek is in de meeste gevallen langer dan de wettelijk voorgeschreven duur van tien weken), er is een tekort aan pleegezinnen, ${ }^{2}$ bij de Raad voor de Kinderbescherming staan kinderen

* Mr. dr. M.P. de Jong-de Kruijf is familie- en jeugdrechtadvocaat bij BVD advocaten.

1. Inspectie Gezondheidszorg en Jeugd, Kwetsbare kinderen onvoldoende beschermd. Toezicht bij de jeugdbescherming en jeugdreclassering, november 2019.

2. In oktober 2019 stonden er zevenhonderd kinderen op de wachtlijst voor pleegzorg (https://www.rtlnieuws.nl/nieuws/nederland/artikel/ 4900521/pleegouders-pleeggezin-pleegzorg-tekort-weekend-deeltijdjeugdzorg).

3. Eind april 2019 wachtten 2.760 kinderen langer dan tien dagen op een onderzoek bij de RvdK (Raad voor de Kinderbescherming, voortgangsrapportage Tertaal 1 2019, juni 2019). Zie tevens Inspectie Justitie en Veiligheid, De wachtlijst bij de Raad voor de Kinderbescherming. Leiden de maatregelen van de RvdK tot het vergroten van het zicht op de veiligheid van het kind en het beperken van de risico's?, december 2018. voor onderzoek op de wachtlijst, ${ }^{3}$ er is een tekort aan gezinsvoogden, ${ }^{4}$ enzovoort.

De Raad voor de Kinderbescherming schrijft hierover op zijn website:

'Waar de ene organisatie de wachtlijst wegwerkt ontstaat bij een ketenpartner een stuwmeer aan problemen. Daarbij komen ook de tekorten op de arbeidsmarkt waar velen van de jeugdzorginstanties mee te maken hebben.' 5

Gesloten geplaatste kinderen op de wachtlijst Kinderen in gesloten jeugdhulp kunnen in veel gevallen ook worden toegevoegd aan de lijst van slachtoffers van de wachtlijstproblematiek. In 2018 luidden ruim vijf-

4. In de zomer van 2019 maken kinderrechters zich grote zorgen over het tekort aan jeugdzorgwerkers. De wachtlijsten bij jeugdbescherming zijn inmiddels zo lang dat het risico bestaat dat er een jaar lang niets gebeurt. Kinderrechters hebben daarom tientallen uitspraken online gezet. Zie bijv. Rechtbank Noord-Nederland 18 maart 2019, ECLI:NL:RBNNE:2019:1465 (de gezinsvoogdijmedewerker is 'Werkvoorraad Lopend Drenthe Zuid'. Machtiging uithuisplaatsing wordt met twee maanden verlengd. Overige deel verzoek aangehouden), Rb. Zeeland-West-Brabant 2 juli 2019, ECLI:NL:RBZWB:2019:3252 (geen gezinsmanager aanwezig en geen recent plan van aanpak, toewijzing OTS voor slechts drie maanden), Rb. Zeeland-West-Brabant 2 juli 2019, ECLI:NL:RBZWB:2019:3249 (OTS voor een jaar opgelegd, uitgevoerd door een zgn. SEK-team), Rb. Zeeland-West-Brabant 17 juni 2019, ECLI:NL:RBZWB:2019:3091 (nog steeds geen jeugdzorgwerker, OTS beperkt tot een maand), Rb. Rotterdam 11 december 2019, ECLI:NL:RBROT:2019:9921 (geen adequate hulp en begeleiding vanuit de GI, korte OTS dan verzocht).

5. Raad voor de Kinderbescherming, Stand van zaken aanpak terugbrengen wachttijden, Nieuwsbericht 24 september 2019 (www.kinder bescherming.nl/actueel/nieuws/2019/09/24/stand-van-zaken-aanpakterugbrengen-wachttijden). 
honderd jeugdrechtadvocaten de noodklok over een tekort aan passende jeugdhulp voor hun minderjarige cliënten, met als gevolg dat kinderen langer dan noodzakelijk is in een instelling voor gesloten jeugdhulp verblijven. Kinderen staan bijvoorbeeld op een wachtlijst voor ambulante behandeling. ${ }^{6}$

Kort en goed rechtvaardigt een wachtlijst voor een vervolgplaatsing geen gesloten plaatsing. In de context van gesloten jeugdhulp is dit des te zorgelijker vanwege het vrijheidsberovende karakter van gesloten jeugdhulp. Dit werd onlangs weer bevestigd door het Hof ArnhemLeeuwarden. ${ }^{7}$

'Het hof stelt vast dat bij een gesloten plaatsing sprake is van vrijheidsbeneming en is van oordeel dat een plaatsing in een gesloten accommodatie voor jeugdzorg een te ingrijpend middel is in een situatie dat sprake is van een wachtlijst voor een plek op de voor [verzoeker] beoogde open groep (r.o. 5.6).'

De wachtlijstproblematiek 'knaagt' aan een scala van kinderrechten van kinderen die met jeugdzorg te maken hebben. Te denken valt aan onder meer de rechten van kinderen die zijn neergelegd in artikel 3 lid 2 en 3, artikel 19, artikel 20 lid 3, artikel 37 en artikel 39 IVRK en artikel 5 lid 1 EVRM.

\section{Jurisprudentie met de rug tegen de muur}

In mijn promotieonderzoek constateer ik dat desondanks sprake is van een wijdverbreide praktijk waarbij het opsluiten van kinderen zijn rechtvaardiging vindt in het doel dat deze kinderen worden opgevoed, die in de Nederlandse context vooral te wijten is aan een gebrek aan passende en realistische alternatieven in de kinderen jeugdpsychiatrie, gespecialiseerde pleegzorg en andere vormen van jeugdbescherming en jeugdhulp. ${ }^{9}$

Dit blijkt onder andere uit gepubliceerde jurisprudentie waarin kinderrechters zeker niet overtuigd zijn van de geschiktheid van gesloten jeugdhulp, maar toch besluiten tot (het continueren van) een gesloten plaatsing. De

6. Brief van de Vereniging van Nederlandse Jeugdrechtadvocaten aan minister De Jonge van VWS, d.d. 21 maart 2018. In het Antwoord op Kamervragen van de leden Westerveld, Buitenweg en Van der Staaij over de gesloten jeugdzorg, zaaknummer 2019D15781, wordt gewezen op het belang van een regionale wachtlijstaanpak.

7. Hof Arnhem-Leeuwarden 27 februari 2020, ECLI:NL:GHARL: 2020:1751. Zie ook hof Arnhem-Leeuwarden 25 juli 2017 ECLI:NL:GHARL:2017:6444 (de omstandigheid dat sprake was van een wachtlijst voor een plek op de voor de verzoeker beoogde open groep mag volgens het Hof niet leiden tot de situatie dat de verzoeker langer gesloten geplaatst blijft, temeer nu bij een gesloten plaatsing sprake is van vrijheidsbeneming).

8. Hof Arnhem-Leeuwarden 27 februari 2020, ECLI:NL:GHARL: 2020:1751. Zie ook Hof Arnhem-Leeuwarden 25 juli 2017, ECLI:NL:GHARL:2017:6444 (de omstandigheid dat sprake was van een wachtlijst voor een plek op de voor de verzoeker beoogde open groep mag volgens het hof niet leiden tot de situatie dat de verzoeker langer gesloten geplaatst blijt, temeer nu bij een gesloten plaatsing sprake is van vrijheidsbeneming).

9. De Jong-de Kruijf, Legitimiteit en rechtswaarborgen bij gesloten plaatsingen van kinderen: de externe rechtspositie van kinderen in gesloten jeugdhulp bezien vanuit kinder- en mensenrechten (diss. Leiden), Den Haag: Boom juridisch 2019, Stelling I. meest moverende reden hiertoe lijkt te zijn dat geen passend alternatief kan worden geboden. ${ }^{10}$

Het gebrek aan een passende (doorstoom)plek voor kinderen in gesloten jeugdhulp is soms zo nijpend dat kinderrechters een machtiging voor gesloten jeugdhulp verlengen in weerwil van het ontbreken van een materiele rechtsgrond uit de Jeugdwet (art. 6.1.2-6.1.4 Jw) of formele rechtswaarborgen die met name in het leven zijn geroepen om het vrijheidsbenemende karakter van een gesloten plaatsing te legitimeren. De motivering van zo'n plaatsing wordt dan gevonden in artikel 3 lid 1 IVRK, namelijk dat de belangen van het kind de eerste overweging vormen.

In deze bijdrage wordt de jurisprudentie besproken waarin artikel 3 lid 1 IVRK 'van stal wordt gehaald' om een gesloten plaatsing van een kind te legitimeren. Welk beeld komt uit deze jurisprudentie naar voren? En is dit een wenselijke praktijk? Deze vragen zijn opnieuw actueel, gelet op twee zeer recente uitspraken van de Rechtbank Rotterdam die hierna ook aan de orde zullen komen.

\section{Uitspraken waarbij niet de Jeugdwet maar enkel artikel 3 lid I IVRK de grondslag vormt voor een gesloten plaatsing}

De Rechtbank Roermond achtte reeds in 2009 een drie maanden durende crisisopvang van een minderjarige zonder zicht op een behandelplaats strijdig met artikel 5 lid 1 EVRM, artikel 3 lid 2 IVRK en artikel 20 IVRK. Toch verlengde de rechtbank de machtiging voor de duur van één maand:

'... vrijheidsbeneming (is) niet langer geoorloofd tenzij een niet verlenging van de machtiging niet in het belang van de minderjarige is op grond van zodanige ernstige opgroei- en opvoedproblemen dat de veiligheid van de minderjarige niet gegarandeerd kan worden bij niet verlenging. In dit verband verwijst de kinderrechter naar het bepaalde in artikel 3, eerste lid van het IVRK dat zegt dat bij alle maatregelen betreffende kinderen de belangen van het kind de eerste overweging vormen.' ${ }^{\text {,1 }}$

In de beschikking wordt benoemd dat sprake is van een grote mate van beïvloedbaarheid van de minderjarige en dat er een gerede kans is dat de minderjarige opnieuw (in ernstige mate) zal ontsporen. Thuisplaatsing bij moeder is ook geen optie en voor plaatsing in een open setting ontbreekt een daartoe strekkend verzoek.

In datzelfde jaar meende de Rechtbank Utrecht dat een voorlopige machtiging gesloten jeugdhulp voor de duur van een nacht en onder strikte voorwaarden in een poli-

10. De Jong-de Kruijf, 2019, p. 286.

11. Rb. Roermond 21 januari 2009, ECLI:NL:RBROE:2009:BH0359. 
tiecel ten uitvoer kon worden gelegd omdat de jeugdige op straat zetten al helemaal geen alternatief zou zijn:

'Vaststaat dat, gelet op de kwetsbaarheid van [naam] en de gevaarlijke situaties waarin zij zichzelf brengt, het volstrekt onverantwoord is dat zij op straat komt te staan.

Tegelijkertijd acht de kinderrechter het onbestaanbaar dat voor [naam], na een hele dag zoeken, in het hele land geen geschikte gesloten plek te vinden is. Het is de kinderrechter bekend dat sinds 1 augustus jl. de tenuitvoerlegging in gevallen als het onderhavige niet meer plaatsvindt in justitiële jeugdinrichtingen. Kennelijk is voldoende opvang op behandelplekken voor crisisgevallen als het thans aan de orde zijnde, ondertussen niet geregeld. Dat als gevolg hiervan de kinderrechter het verzoek bereikt dat de tenuitvoerlegging dan als laatste uitvlucht in een politiecel moet plaatsvinden, past op geen enkele wijze in het beleid van de bevoegde instanties, nu plaatsing in een politiecel bezwaarlijk als een verbetering ten opzichte van een justitiële jeugdinrichting kan worden aangemerkt.

De kinderrechter acht zich door de gang van zaken voor het blok gezet en kan in het belang van [naam] geen enkel ander besluit nemen dan het verzoek in te willigen, de formele bevoegdheid daartoe en de inhoudelijke gronden daartoe baserend op artikel 3 IVRK, nu de andere mogelijkheid, namelijk het verzoek afwijzen en [naam] daarmee met al haar hulpeloosheid op straat te zetten, eenvoudigweg geen optie is.' 12

De Rechtbank Rotterdam verleende in 2015 een machtiging uithuisplaatsing voor de duur van twee maanden in een gesloten instelling. Strikt genomen volstaat een reguliere machtiging uithuisplaatsing niet voor een gesloten plaatsing, maar in de beschikking valt te lezen dat:

'Alle betrokken partijen, waaronder de minderjarige zelf, zijn het echter eens dat het verblijf van de minderjarige bij Schakenbosch moet worden voortgezet totdat er een plek voor haar is gevonden in een open instelling voor jeugdhulp. Om die reden zal de kinderrechter in navolging van het advies van de bijzonder curator met toepassing van artikel 3 van het Verdrag inzake de rechten van het kind (IVRK), welke bepaling voorschrijft dat ook bij rechterlijke beslissingen de belangen van het kind de eerste overweging vormen, het verzoek van de GI toewijzen.' ${ }^{\text {'13 }}$

In twee andere zaken is niet voldaan aan een formeel vereiste voor een gesloten plaatsing, namelijk instemming van een onafhankelijke gedragswetenschapper. De Rechtbank Middelburg beriep zich op 10 november 2011 op het IVRK omdat strikte toepassing van de wet zou indruisen tegen artikel 3 lid 1 IVRK. Strikte toepas- sing zou namelijk inhouden dat het verzoek zou moeten worden afgewezen omdat de gedragswetenschapper die de jeugdige had onderzocht, niet had ingestemd. Immers, de jeugdige zou bij strikte toepassing van de wet naar huis behoren te gaan, maar daar was de kans op verder afglijden zeer groot aanwezig. Zowel de jeugdige als zijn ouders stemden overigens wel in met het verlengingsverzoek. ${ }^{14}$

De Rechtbank Groningen hanteerde een vergelijkbare argumentatie in 2012:

'De kinderrechter is van oordeel dat in onderhavig geval strikte toepassing van de Wet op de jeugdzorg zich niet verhoudt tot hetgeen in artikel 3, lid 1 IVRK staat vermeld, omdat dat niet in het belang van [de minderjarige] is. In geval van strikte toepassing zou het hem ontbreken aan passende begeleiding en behandeling die hij gelet op de aard en ernst van zijn problematiek en het onttrekken aan hulpverlening nodig heeft in een gesloten setting. [de minderjarige] zou bij het ontbreken van alternatieve woonplekken, waarvan ook nog maar moet worden afgewacht of deze toereikend zullen zijn, zeer waarschijnlijk bij zijn grootmoeder komen te wonen. De WSG heeft aangevoerd dat het risico dat het dan binnen korte tijd weer mis zal gaan en hij opnieuw in aanraking zal komen met politie en justitie, zeer groot aanwezig is. De kinderrechter deelt deze visie en is gezien de problematiek van [de minderjarige] en het feit dat een eerdere plaatsing bij de grootmoeder is mislukt, van oordeel dat de grootmoeder hem niet die bescherming en veiligheid kan bieden die voor hem noodzakelijk is. Een ander alternatief voor opvang van [de minderjarige] is op dit moment niet voorhanden.' ${ }^{15}$

\section{Twee recente uitspraken van de rechtbank Rotterdam}

Op 7 februari 2020 oordeelde de Rechtbank Rotterdam over een verzoek tot een gesloten machtiging waarvan de gronden voor dit verzoek volgens de verzoekende partij (de GI) niet langer gevonden konden worden in artikel 6.1.2 lid $2 \mathrm{Jw}$. De gesloten instelling zelf gaf aan dat als de gesloten machtiging niet zou worden verlengd, het kind, in het beste geval, waarschijnlijk naar een crisisopvangvoorziening zou worden gebracht. Ter zitting heeft de kinderrechter de optie van een kort geding (om een plaats in een open instelling af te dwingen) afgewogen maar verworpen. De gedragswetenschapper is ambivalent: er zijn volgens haar geen redenen om met het verzoek van de GI in te stemmen, maar het kind voelt zich vertrouwd en veilig in de gemeente waarin de gesloten instelling staat. De kinderrechter woog de belangen van het kind tegen elkaar af, gaf een gesloten machtiging af voor de duur van drie maanden (ter overbrugging) en onderbouwde dit als volgt: 
'Het belang van [naam kind] bij die machtiging is duidelijk. Voor zover voor deze beslissing een grondslag moet worden gevonden, ligt die in artikel 3, eerste lid, van het IVRK.'16

Een paar dagen eerder oordeelde de Rechtbank Rotterdam ten aanzien van een meerderjarige ook dat het belang van het kind zich niet verzet tegen een gesloten plaatsing, ook al is niet voldaan an artikel 6.1.2 lid 4 sub $\mathrm{b}$ en $\mathrm{c} \mathrm{Jw}$ (er is geen hulpverleningsplan vastgesteld voor de $18^{\mathrm{e}}$ verjaardag en er wordt niet toegewerkt naar een andere vorm van jeugdhulp dan gesloten jeugdhulp). De kinderrechter merkte hierover op:

'het is toch wel heel treurig dat als gevolg van de wachtlijstproblematiek een jong-meerderjarige tegen zijn wil gesloten geplaatst moet blijven, zonder dat aan alle wettelijke vereisten voor een dergelijke plaatsing is voldaan. ${ }^{17}$

In de beschikking legt de kinderrechter uit voor welk dilemma hij zich ziet geplaatst:

$\mathrm{Er}$ is geen duidelijkheid over een vervolgplek. [naam kind] is er niet bij gebaat om hem zonder perspectief bij Schakenbosch te laten verblijven. Het is echter ook van belang om te voorkomen dat hij op straat komt te staan.

De rechtbank gaf een machtiging af voor de duur van de verzochte zes maanden.

Blijkbaar is de situatie in sommige gevallen soms zo nijpend dat kinderrechters zich noodgedwongen verlaten op artikel 3 lid 1 IVRK bij wijze van allerlaatste redmiddel.

\section{Lessen uit General Comment no. 14 over art. 3 lid 1 IVRK}

In deze zeven uitspraken wordt artikel 3 lid 1 IVRK gebruikt om de Jeugdwet te overrulen. 'Te strikte toepassing' is een gebruikte term. Ook wordt nogal eens de opmerking gemaakt dat het alternatief anders de straat zou zijn, en dan is - zo wordt geredeneerd - een gesloten plaatsing altijd nog beter. Je kunt op meerdere manieren kijken naar deze uitspraken. Enerzijds zou men kunnen bepleiten dat hieruit maar weer eens blijkt hoe nijpend de situatie is en hoe duivels het dilemma voor kinderrechters is. In die zin kunnen deze uitspraken een toelaatbaar signaal afgeven over de ernst van de situatie. Anderzijds is de lijn van het Gerechtshof Arnhem-Leeuwarden verdedigbaar: als de Jeugdwet niet voorziet in de wachtlijstproblematiek als rechtsgrond voor een gesloten plaatsing, dan geldt dat voor artikel 3 lid 1 IVRK ook niet. Daarnaast geldt mijns inziens dat een formele wet wordt getoetst aan het $\mathrm{VN}$ Kinderrechtenverdrag. De wet vervolgens opzijzetten

16. Rb. Rotterdam 7 februari 2020, ECLI:NL:RBROT:2020:1337.

17. Rb. Rotterdam 3 februari 2020, ECLI:NL:RBROT:2020:1184. en artikel 3 lid 1 IVRK ervoor in de plaats stellen, conflicteert daarmee.

Bestudering van General Comment no. 14 van het VNKinderrechtencomité over artikel 3 lid 1 IVRK $^{18}$ leert ons dat 'de belangen van het kind' een flexibel begrip vormt zodat het begrip in vele, individuele situaties van toepassing kan zijn. Direct daarna wordt gewaarschuwd dat het begrip ook ruimte kan bieden an manipulatie (para. 34). Vervolgens werkt het VN-Kinderrechtencomité een beslismodel uit voor het afwegen van de belangen van het kind dat bestaat uit twee stappen:

\section{Stap 1 \\ 'First, within the specific factual context of the case, find out what are the relevant elements in a best-interests assessment, give them concrete content, and assign a weight to each in relation to one another;' \\ Stap 2 \\ 'Secondly, to do so, follow a procedure that ensures legal guarantees and proper application of the right.'}

In stap 1 moeten de volgende elementen onderzocht worden: de mening van het kind, de identiteit van het kind, behoud van eigen omgeving en familierelaties, bescherming en veiligheid, de kwetsbare situatie waarin het kind zich bevindt, het recht op gezondheid en onderwijs (para. 52-79). Relevant voor de wachtlijstproblematiek is dat een beslissing niet alleen moet worden genomen aan de hand van de actuele situatie, maar ook aan de hand van mogelijke toekomstige scenario's. ${ }^{19}$ In de uitspraak van de Rechtbank Rotterdam op 7 februari 2020 benoemt de gedragswetenschapper bijvoorbeeld dat de onzekerheid over het plaatsingsperspectief spanningen teweegbrengen bij het kind.

Stap 2 kent de volgende onderdelen: het recht van het kind om zijn mening te geven, feitenonderzoek, de perceptie van tijd, gekwalificeerde professionals, procesvertegenwoordiging, strakke juridische argumentatie (motivering), beroepsmogelijkheid, en een kinderrechtenimpact-toets. Twee opmerkingen hierbij. De beslissing die wordt genomen moet aansluiten bij de perceptie van tijd van het kind. Het valt op dat in vrijwel alle hiervoor besproken uitspraken een machtiging voor kortere duur wordt afgegeven. $\mathrm{Zij}$ het dat een machtiging voor de duur van de verzochte zes maanden voor nota bene een meerderjarige rijkelijk lang is. Als het gaat over de toets van de kinderrechtenimpact, dan vrees ik dat wanneer de uitspraken langs deze meetlat worden gelegd, het nogal een waagstuk is om artikel 3 lid 1 IVRK te isoleren van andere kinderrechten. Artikel 3 lid 1 IVRK staat immers nooit op zichzelf, maar 'tandemt' met andere kinderrechten. Als alle kinderrechten van het kind conflicteren met een beslissing, behalve met het

18. VN-Kinderrechtencomité, General comment No. 14 (2013) on the right of the child to have his or her best interests taken as a primary consideration (art. 3, para. 1), CRC/C/GC/14, 29 mei 2013.

19. '...but should also consider the possible scenarios of the child's development, and analyse them in the short and long term. In this context, decisions should assess continuity and stability of the child's present and future situation.' (para. 84) 
recht van het kind dat zijn belangen de eerste overweging vormen, dan roept dat serieuze vragen op over de legitimiteit van de beslissing.

\section{Afsluiting}

De wachtlijstproblematiek is al heel lang een issue in de Nederlandse jeugdzorg. Het VN-Kinderrechtencomité merkte al in 1999 op bezorgd te zijn over 'the long maiting periods for placement in the residential care'. Vervolgens herhaalt het Comité in 2004, 2009 en 2015 dat er onvoldoende gehoor is gegeven aan deze opmerking. ${ }^{20}$

Wachten op een passende plek knaagt aan de rechten van het gesloten geplaatste kind. Juist en vooral omdat sprake is van niet-gelegitimeerde vrijheidsberoving; vanuit een kinderrechtenperspectief een onverenigbaar begrippenpaar. Ik acht de ontsnappingsroute via artikel 3 lid 1 IVRK niet geheel onmogelijk, mits er grondig gemotiveerd wordt conform de handvatten die het Comité daartoe aanreikt. Dit advies geldt niet alleen de rechterlijke macht, maar ook de onafhankelijke gedragswetenschappers die een instemmingsverklaring moeten opstellen.

Alles overziend lijkt mij dat de route via artikel 3 lid 1 IVRK op korte termijn wat lucht kan geven aan een individuele, precaire situatie. Deze route heeft echter nog nooit geleid tot langetermijnoplossingen, laat staan tot verbeteringen van het systeem.

20. Meest recent: VN-Kinderrechtencomité, Concluding observations on the fourth periodic report of the Netherlands, CRC/C/NLD/CO/4, 8 juni 2015. 